\title{
Design of SARS-CoV-2 hFc-Conjugated Receptor-Binding Domain mRNA Vaccine Delivered via Lipid Nanoparticles
}

\author{
Uri Elia, Srinivas Ramishetti, Ronit Rosenfeld, Niels Dammes, Erez Bar-Haim, Gonna Somu Naidu, \\ Efi Makdasi, Yfat Yahalom-Ronen, Hadas Tamir, Nir Paran, Ofer Cohen,* and Dan Peer*
}

Cite This: https://dx.doi.org/10.1021/acsnano.0c10180

Read Online

\section{ACCESS |}

Wl Metrics \& More

Article Recommendations

Supporting Information

ABSTRACT: Severe acute respiratory syndrome coronavirus 2 (SARS-CoV-2) has been identified as the causal agent of COVID-19 and stands at the center of the current global human pandemic, with death toll exceeding one million. The urgent need for a vaccine has led to the development of various immunization approaches. mRNA vaccines represent a cell-free, simple, and rapid platform for immunization, and therefore have been employed in recent studies toward the development of a SARS-CoV-2 vaccine. Herein, we present the design of an mRNA vaccine, based on lipid nanoparticles (LNPs)-encapsulated SARS-CoV-2 human Fc-conjugated receptorbinding domain (RBD-hFc). Several ionizable lipids have been evaluated in vivo in a luciferase (luc) mRNA reporter assay, and two leading LNPs formulations have been chosen for the subsequent RBD-hFc mRNA vaccine strategy. Intramuscular administration of LNP RBD-hFc mRNA elicited robust humoral response, a high level of neutralizing antibodies and a Th1-biased cellular response in BALB/c mice. The data in the current study demonstrate the potential of these lipids as promising candidates for LNP-based mRNA vaccines in general and for a COVID19 vaccine in particular.

KEYWORDS: SARS-CoV-2, COVID-19, mRNA vaccine, lipid nanoparticles, ionizable lipids

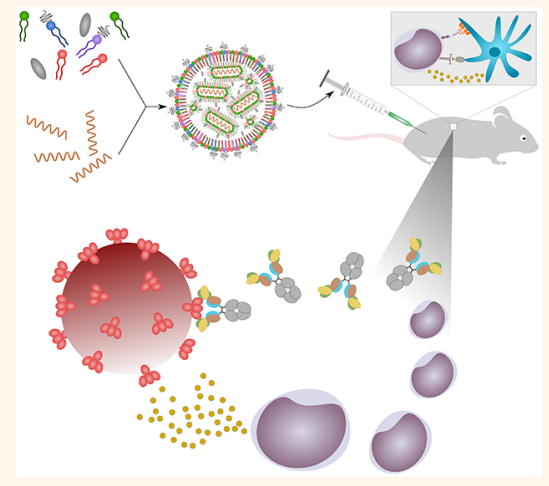

evere acute respiratory syndrome coronavirus 2 (SARS$\mathrm{CoV}-2$ ), is a coronavirus identified as the etiological agent of coronavirus disease 19 (COVID-19). This coronavirus stands at the center of the current global human pandemic, with recent reports of more than 36 million cases and over one million deaths worldwide. ${ }^{1}$ The urgent need for a vaccine has led to an unprecedented recruitment of academic laboratories, hospitals, and pharmaceutical companies around the world, which translated into a wide array $(>180)$ of preclinical and clinical studies being conducted in an effort to develop an effective vaccine against SARS-CoV-2. These vaccine candidates can be classified into several categories: inactivated/live attenuated virus, recombinant viral vector, recombinant protein, DNA vaccine, and mRNA (mRNA) vaccine.

The mRNA vaccine platform has been developed extremely rapidly in the past few years, mainly due to advances in mRNA stabilization and the introduction of efficient delivery methods that originated largely from the siRNA field. mRNA vaccines hold several advantages over traditional vaccine approaches: This platform poses no potential risk of infection or genome integration, does not require entry to the nucleus, and can be developed very rapidly and easily. This last advantage has been demonstrated very clearly in the current COVID-19 pandemic, with the development of an mRNA vaccine by Moderna Inc. directed against the spike protein of SARS-CoV-2, with only 66 days from sequence selection to first human dosing. ${ }^{3}$

One of the main challenges in mRNA therapy is efficient delivery of mRNA to target cells and tissues. High susceptibility to degradation by omnipresent ribonucleases (RNases), together with inherent negative charge, hinder the successful delivery of mRNA to cells and subsequent translocation across the negatively charged cell membrane. Hence, successful mRNA delivery requires a carrier molecule which will protect it from degradation and facilitate cellular uptake. Several nanoparticle systems have been developed for efficient nucleic acid delivery, among them lipid nanoparticles (LNPs) are a clinically advanced, nonviral delivery system for

Received: December 5, 2020

Accepted: January 21, 2021 
A

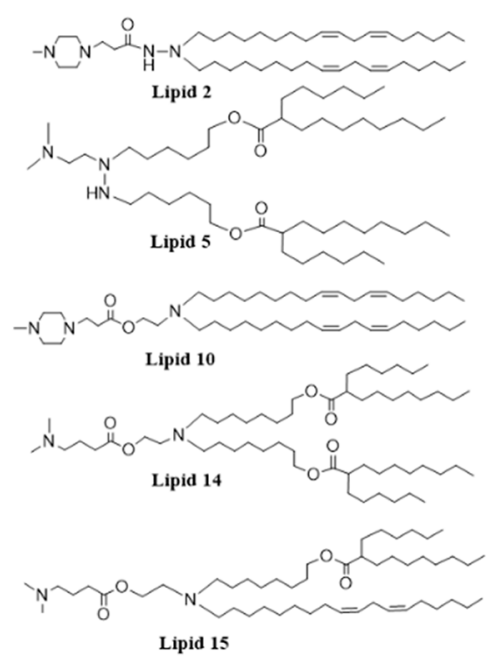

B

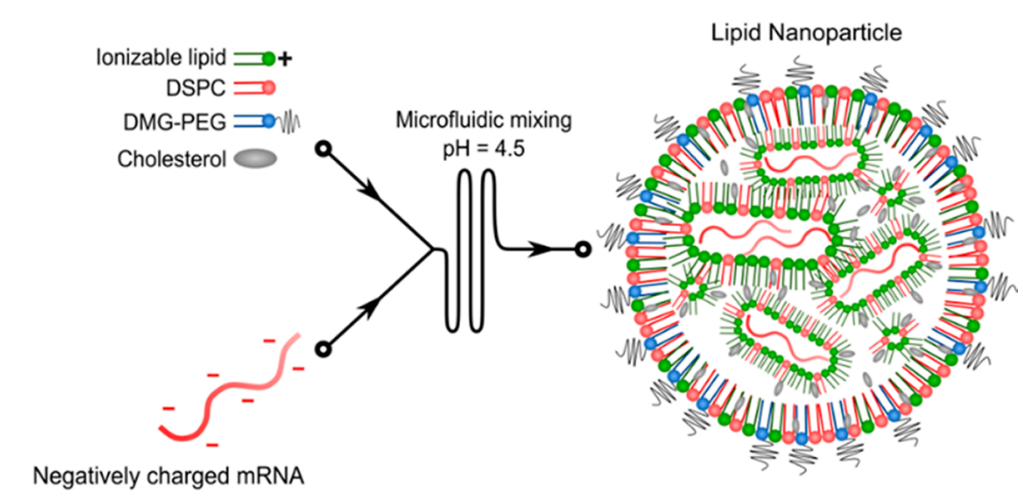

Negatively charged mRNA

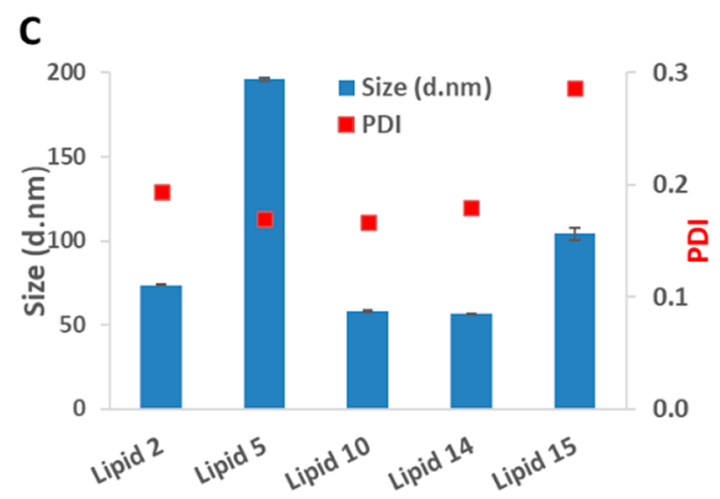

D
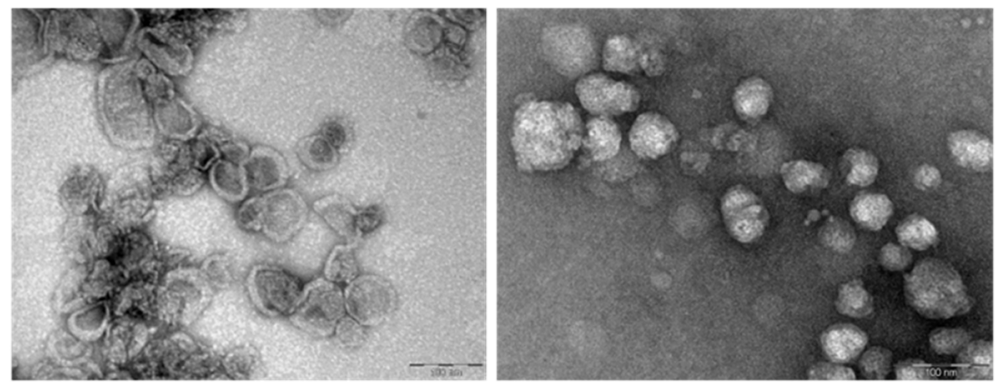

Figure 1. Chemical structures and physicochemical properties of the designed LNPs. (A) Schematic illustrations of the structures of the lipids. (B) Schematic illustration of LNP synthesis. (C) Representative size distribution and polydispersity index (PDI) of LNPs measured by dynamic light scattering. (D) Representative TEM images of LNP \#2 and LNP \#14, respectively. Scale bar $100 \mathrm{~nm}$. Weight ratios of 1:23 (mRNA to lipid) were used in LNP synthesis.

siRNA, approved by the U.S. Food and Drug Administration (FDA). ${ }^{4}$ However, in the past few years, LNPs have emerged as one of the most advanced and efficient mRNA delivery platforms. LNPs are comprised of multiple lipid components including ionizable amine lipid, phospholipid, cholesterol, and PEG lipid. Ionizable amine lipid is a key component of LNPs, which affects nucleic acid encapsulation efficiency and plays an important role in endosomal escape of nucleic acid from LNPs following cellular uptake. ${ }^{5-7}$ Recent reports demonstrated antigen-encoded mRNA encapsulated in lipid nanoparticles (mRNA-LNPs) as a potent vaccine platform for several infectious diseases including viral infections such as HIV, CMV, rabies, influenza, zika, and most recently SARS-CoV$2^{3,8-13}$

Herein, we synthesized several structurally different ionizable lipids and screened for in vivo mRNA-LNPs delivery in the form of LNPs for vaccine applications. The screen yielded two LNP formulations, which were chosen for further immunization studies using SARS-CoV-2 RBD-hFc mRNA. These experiments demonstrated the development of a specific humoral and cellular response toward the RBD, as well as neutralizing antibodies that blocked viral infection in a spikepseudotyped VSV plaque reduction neutralization test (PRNT). Finally, Th1-/Th2-specific cytokine secretion was evaluated in response to LNP RBD-hFc mRNA vaccination.

\section{RESULTS AND DISCUSSION}

LNPs Preparation and Physicochemical Characterization. The structures of the amino lipids used in this work are shown in Figure 1A and were synthesized according to standard synthetic procedures discussed in Supporting Information (Figure S1). These structurally different lipids were selected from our previous work. ${ }^{14}$ LNPs were produced by mixing of the lipids and mRNA through a microfluidic mixture device. A schematic illustration of LNP synthesis is shown in Figure 1B and described in detail in Methods. The resultant mRNA-LNPs were small and uniformly distributed as evidenced by small hydrodynamic diameters and polydispersity indexes (PDIs), measured by dynamic light scattering (DLS) (Figure 1C). Except lipid 5, the mean size of the LNPs was less than $100 \mathrm{~nm}$ in diameter. Additional analysis performed using transmission electron microscopy (TEM) supported the DLS data, showing small and uniform size distribution of the particles (Figure 1D).

In Vivo Luciferase Expression Screen Showing Two Distinct Formulations with Superior Protein Expression. In order to evaluate the in vivo efficiency of the LNPs in terms of distribution, protein expression efficiency, and kinetics, we conducted a luciferase mRNA-based in vivo screen. Animals were injected via intradermal (i.d.), intramuscular (i.m.), or subcutaneous (s.c.) routes with $5 \mu \mathrm{g}$ of luciferase-mRNA encapsulated with one of the five LNP-based 
A

LNP-based
formulation

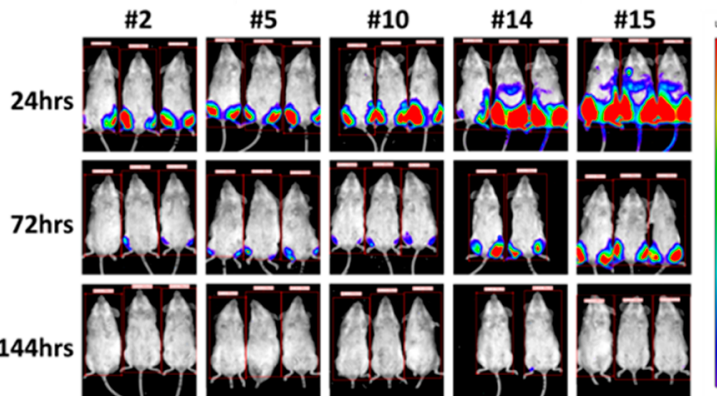

B

LNP-based

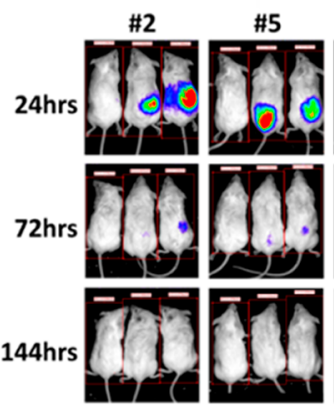

Subcutaneous
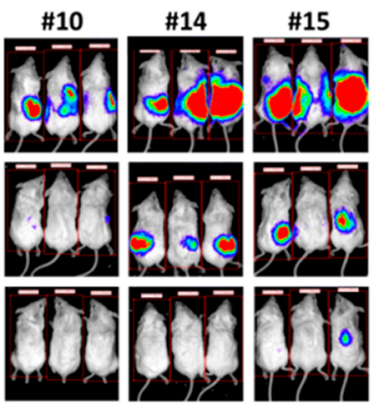

C

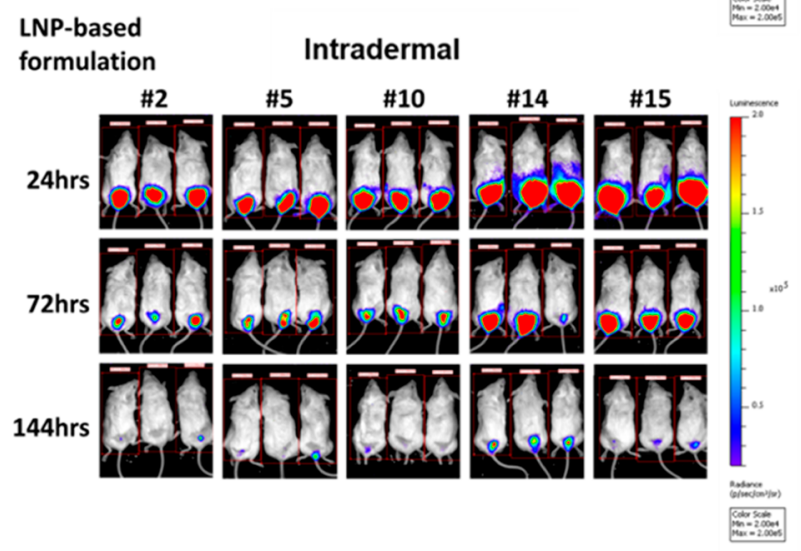

D

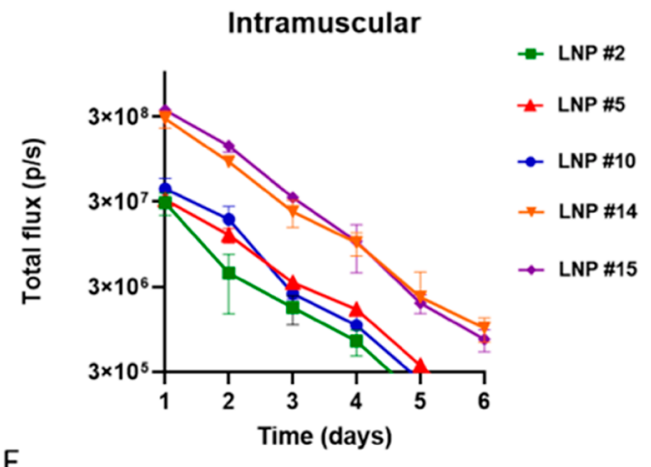

E

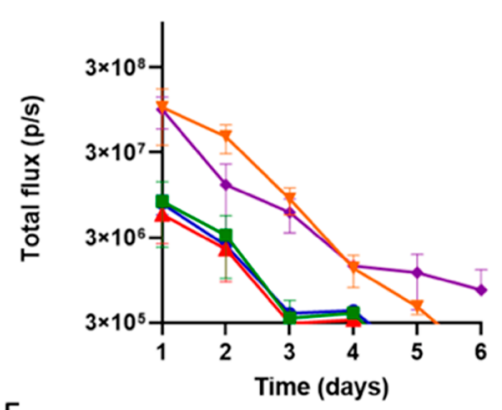

Intradermal

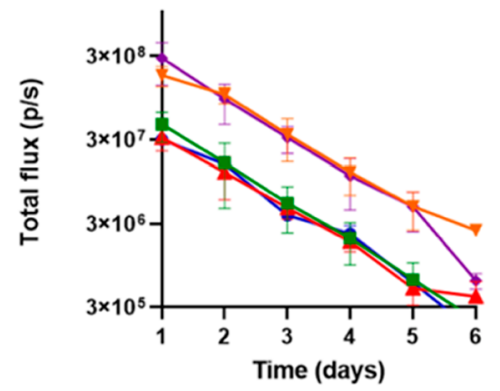

Figure 2. In vivo expression pattern of LNP-encapsulated luc mRNA. Representative IVIS images of groups of female BALB/c mice injected with $5 \mu \mathrm{g}$ of luc mRNA encapsulated by five LNP formulations by the intramuscular (A), subcutaneous (B), and intradermal (C) routes. (DF) Quantification of the bioluminescent signal detected throughout 6 days of monitoring.

formulations, represented herein as LNP \#2, \#5, \#10, \#14, and $\# 15$, and luciferase expression was evaluated daily using IVIS. As shown in Figure 2, LNPs \#14 and \#15 were superior to other formulations in terms of protein expression level and its duration in all three routes of administration and therefore were chosen for further experiments. Interestingly, lipid \#10, previously shown superior for RNAi delivery, was less effective in delivering mRNA. We chose to proceed also with LNPs \#2, in order to eliminate the possibility of a discrepancy between in vivo luciferase expression and the resulting immunologic response. Additionally, since i.d. and i.m. injections exhibited higher and more prolonged protein expression, further immunization studies were conducted using these routes of administration.

Immune Response to Luciferase Expression. Next, we examined the immune response that developed toward the luciferase protein. Intramuscular-immunized mice were bled and sacrificed 4 weeks after immunization with LNPencapsulated luciferase mRNA. Antiluciferase antibodies were detected by ELISA, and luciferase-specific cellular response was evaluated by ELISpot. While the humoral response was limited, with no statistically significant differences between the vaccinated animals and the control naive mice, as expected after a single dose administration (Figure 3A), a substantial cellular response was detected when splenocytes were stimulated with the luciferase protein. Interestingly, immunization with LNPs \#2 and \#14 led to a strong cellular response; however, no statistically significant difference was recorded in LNPs \#15-treated mice when compared to naive animals (Figure 3B). On the basis of these results, we decided to perform the following vaccinations with the two leading formulations, \#2 and \#14.

Immune Responses in RBD-hFc mRNA-Vaccinated Mice. Similar to SARS-CoV, the SARS-CoV-2 virus recognizes 
A

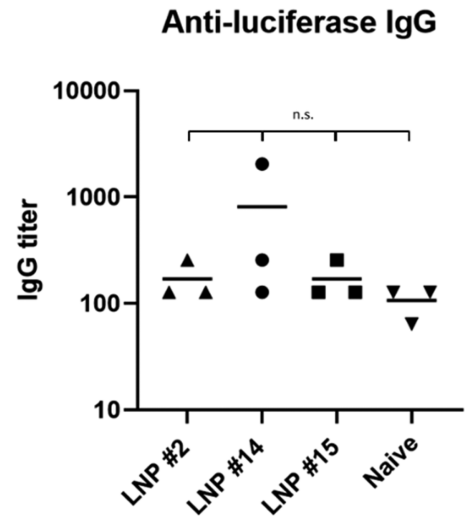

B

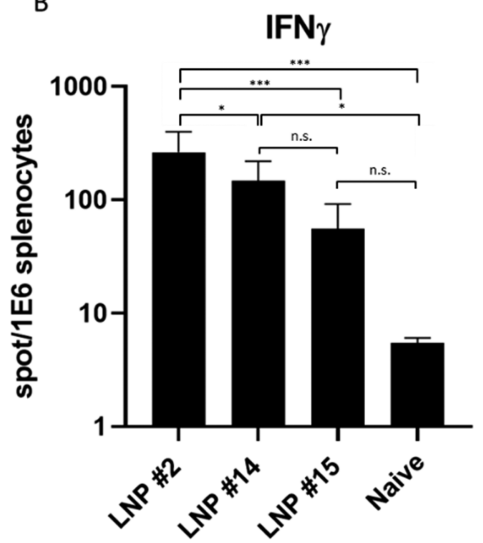

Figure 3. In vivo luciferase expression leading to specific cellular immune response. Female BALB/c mice were intramuscularly administered with $5 \mu \mathrm{g}$ of LNPs-luc mRNA or untreated (naive). Sera and spleen samples collected 28 days postadministration for evaluation of luciferasespecific humoral (A) and cellular response (B), as described in Methods. Statistical analysis was performed using one-way ANOVA followed by post hoc Newman-Keuls test (n.s., not significant; *, $p<0.05$; $* *, p<0.01$; ***, $p<0.001$ ).

angiotensin-converting enzyme 2 (ACE2) as receptor for host cell entry. SARS-CoV-2 spike (S) protein consists of $S 1$, including receptor-binding domain (RBD), which specifically recognizes the ACE2 receptor and plays a crucial role in mediating viral entry into cells, and S2 subunits. ${ }^{15}$ For our vaccine platform, we chose the RBD of SARS-CoV-2 as the target antigen for the mRNA coding sequence, as described in Methods. Fusion of the IgG-Fc domain to a protein of interest has been shown to increase the half-life, immunogenicity, solubility, and delivery efficiency of the targeted protein. ${ }^{16-20}$ Fc-fusion products are commonly used in the clinic, and 13 products have been approved by the FDA and European Medicines Agency (EMA) to date. ${ }^{21}$ Given the potential benefits of $\mathrm{Fc}$-fusion proteins in promoting immune responses, we chose to perform the vaccination experiments with $\mathrm{Fc}$ fused both as mRNA and as a recombinant protein.

Mice were immunized i.m. or i.d. with either naked RBDhFc mRNA $(5 \mu \mathrm{g})$ or LNPs-encapsulated (\#2 or \#14) RBDhFc mRNA $(5 \mu \mathrm{g})$. Control experimental groups were immunized with empty LNPs or recombinant hFc-RBD protein (rRBD-hFc; s.c., $10 \mu \mathrm{g}$ ). In all groups, a prime-boost vaccination regimen was employed, with animals being primed at day 0 and boosted 25 days later. Blood and spleen samples were collected at days 23 (preboost) and 39 (14 days postboost) for evaluation of immune responses (see outline in Figure 4A).

As shown in Figure 4B, preboost humoral response against SARS-CoV-2 spike was limited, both in mRNA (naked or LNP-encapsulated) and rRBD-hFc-vaccinated mice. However, a robust antibody response could be detected 14 days after the boost in both LNP-encapsulated mRNA and recombinant protein experimental groups, whereas no response was observed in the naked mRNA group. While both LNP formulations exhibited a boost effect at the i.m. route, a differential antibody response was observed at the i.d. route between LNP \#2- and \#14-encapsulated RBD-hFc mRNA, with only the latter yielding a substantial anti-RBD titer $(>10,000)$ (Figure 4B). Most importantly, this differential response was also evident in the postboost spike-pseudotyped VSV neutralizing assay, where i.d. LNP \#14-encapsulated RBD-hFc mRNA vaccination induced a significant neutralizing response, while no neutralizing activity was apparent in LNP \#2-encapsulated RBD-hFc mRNA vaccinated mice (Figure
4C). Immunization with $\mathrm{rRBD}-\mathrm{hFc}$ also led to a robust boost effect in terms of antispike antibody titer and neutralization. Interestingly, no significant difference was observed between vaccinations with $\mathrm{rRBD}-\mathrm{hFc}$ protein alone or in the presence of the CFA/IFA adjuvant. The high antibody titer and neutralizing effect elicited by the recombinant protein in the absence of an adjuvant can be attributed to the robust adjuvant effect of Fc, and should be investigated further in a separate study.

The cellular immune response to SARS-CoV-2 plays a crucial role in the ability of the immune system to overcome infection. $^{22,23}$ We thus evaluated the cellular response that developed after immunization with LNP-encapsulated RBD$\mathrm{hFc}$ or rRBD-hFc by using the ELISpot method for quantification of IFN $\gamma$-secreting cells. In contrast to the humoral response, which was very limited before boost administration, a clear specific cellular response could be observed 23 days after priming, particularly in mice that were vaccinated via the i.m. route.

A significant increase in specific cellular response was observed after boost administration in both i.m. and i.d. routes of administration, and in both LNP formulations of the RBDhFc mRNA. Conversely, immunization of mice with recombinant $\mathrm{RBD}-\mathrm{hFc}$ did not lead to a significant cellular response, and the postboost elevation in IFN $\gamma$ secretion was not statistically significant (Figure 4D).

We next evaluated the Th1/Th2 cytokine secretion profile of LNP RBD-hFc mRNA-vaccinated mice. As shown in Figure 5 (and Figure 4D of ELISpot results for IFN $\gamma$ response), a specific and statistically significant secretion of IFN $\gamma$ and IL-2 was observed in vaccinated mice compared to vehicle treatment, both before and after boost administration. In contrast, Th2 cytokines were either below the limit of detection (IL-4) or in comparable levels in vaccinated versus vehicle-treated animals (IL-10).

Severe acute respiratory syndrome coronavirus 2 (SARSCoV-2) has recently emerged as a global pandemic, risking most of the earth's population health and leading toward a worldwide economic crisis since its outbreak. Numerous vaccination platforms have been recently employed in the quest for an effective vaccine against the virus. mRNA-based vaccines have been extensively explored in the past few years for immune therapy applications and viral infections. Due to its 
A

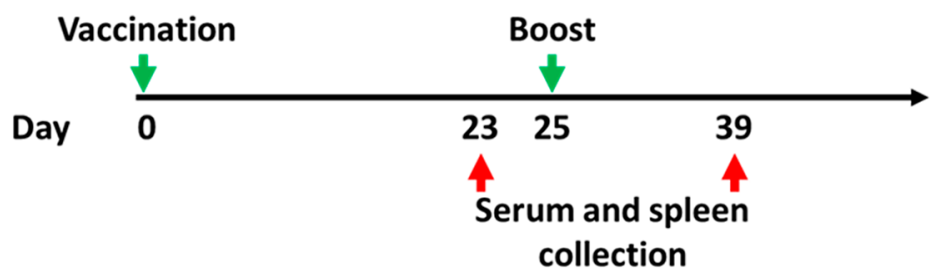

B

RBD-mRNA

Intramuscular vaccination

Binding antibodies

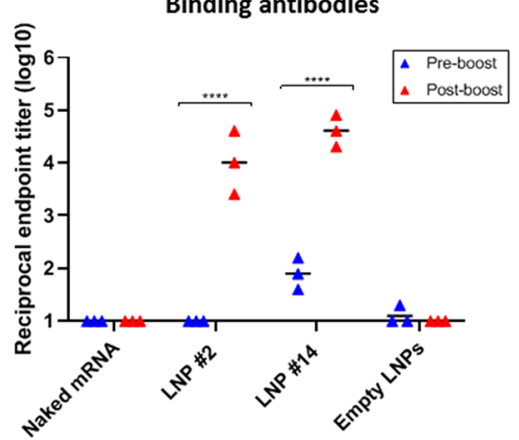

C
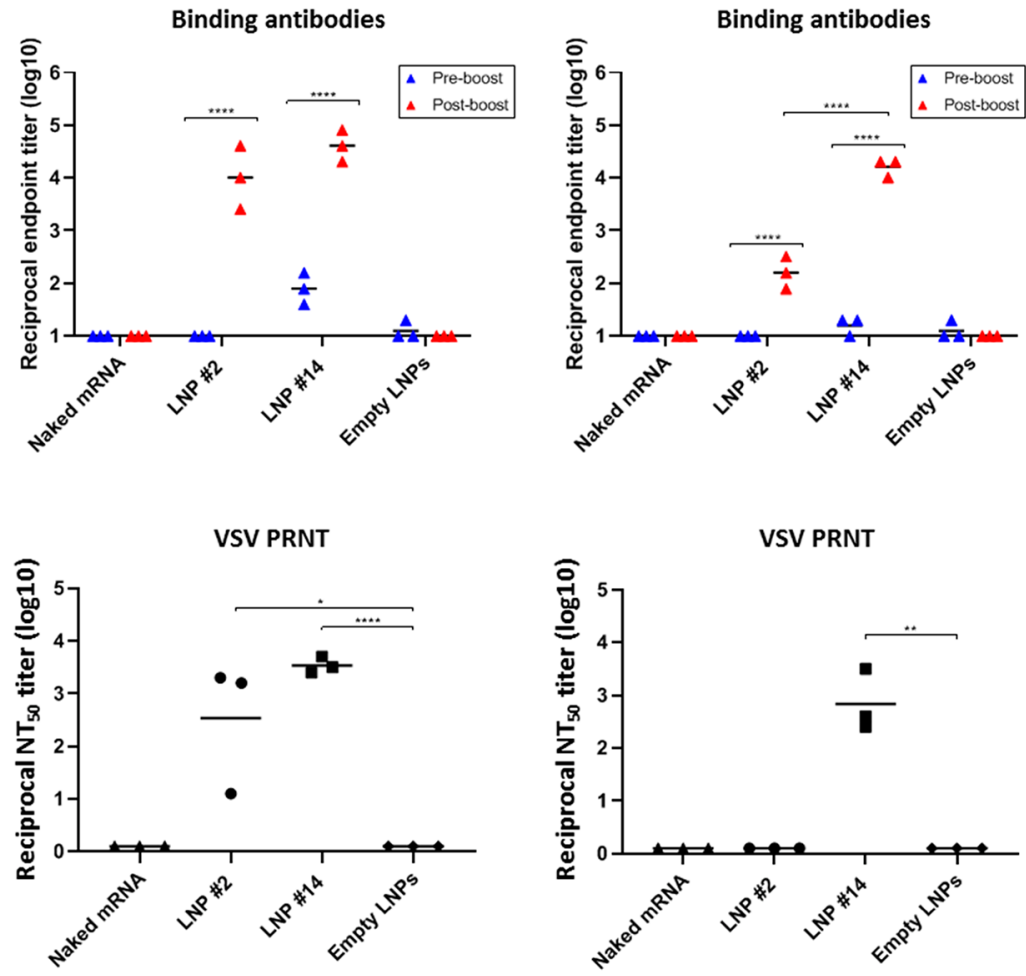

Cellular response

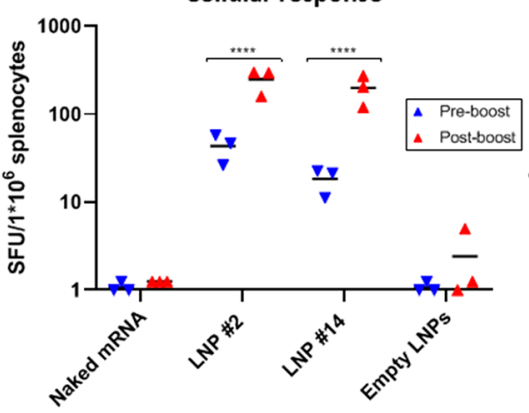

D

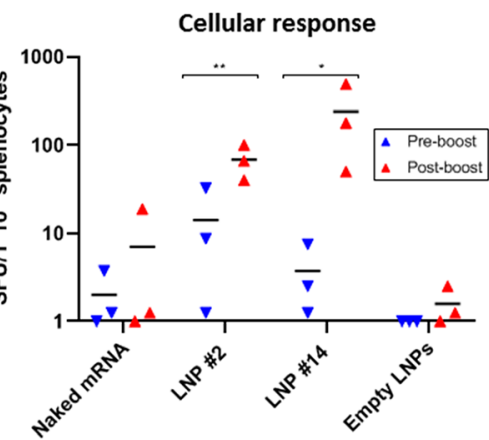

VSV PRNT

Intradermal vaccination

Binding antibodies
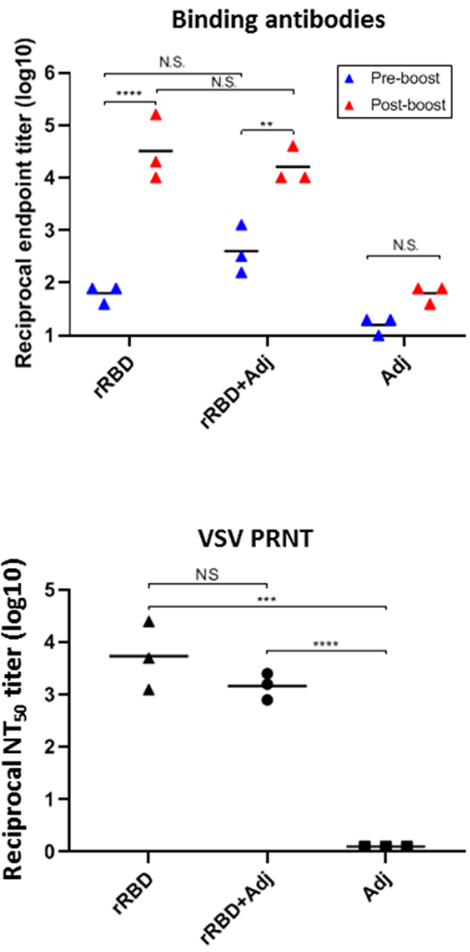

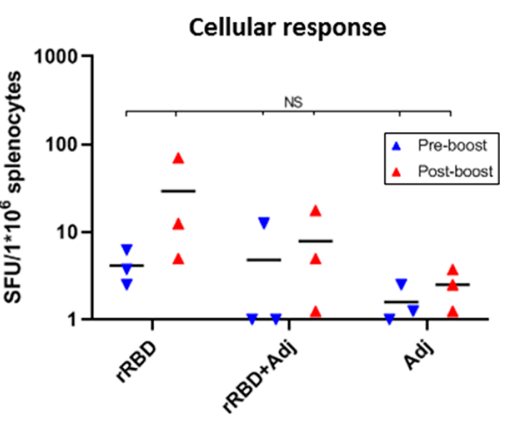

Figure 4. Immunization of mice with LNPs RBD-hFc mRNA leading to a robust immune response. Female BALB/c mice were immunized either i.m. or i.d. with $5 \mu \mathrm{g}$ of LNPsRBD-hFc mRNA or s.c. with $10 \mu \mathrm{g}$ of rRBD-hFc and boosted with an equivalent dose 25 days later. Serum and spleen were collected at days 23 ("preboost") and 39 ("postboost") after initial vaccination. (A) Schematic diagram of immunization and sample collection. (B) SARS-CoV-2 spike-specific IgG antibody titer determined by ELISA. (C) NT 50 titers determined postboost using a VSV-based pseudovirus PRNT assay. (D) SARS-CoV-2 spike-specific cellular response determined by ELISpot. Statistical analysis was performed using a two-way ANOVA with Tukey's multiple comparisons test (for ELISA data) or an unpaired two-tailed Student's $t$ test (for PRNT and ELISpot data) (*, $p<0.05$; **, $p<0.01$; **, $p<0.001$; ***, $p<0.0001$ ). 

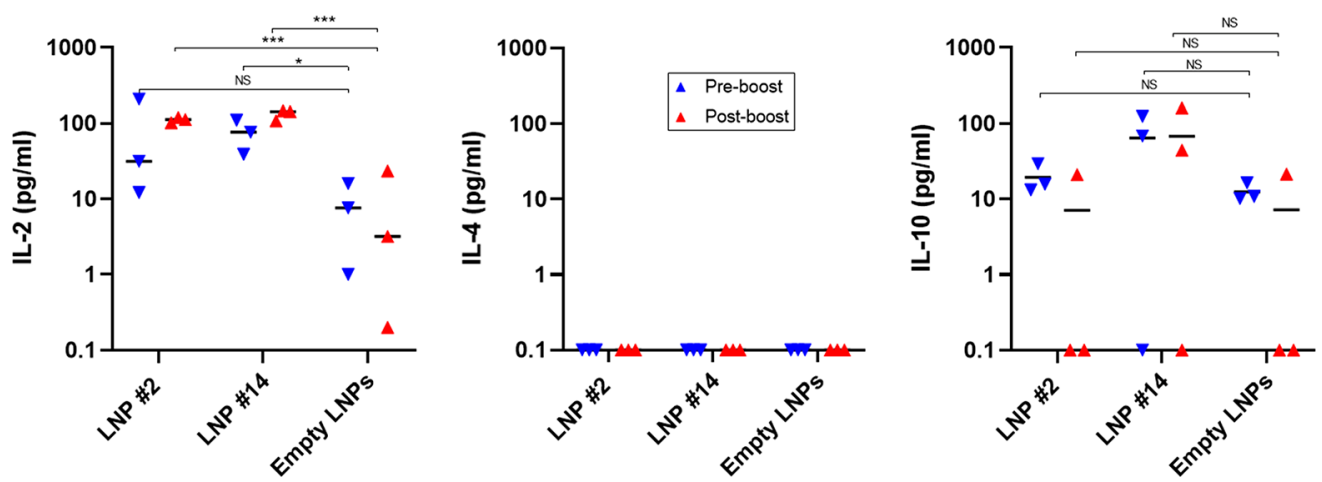

Figure 5. Cytokine profile of induced responses. Splenocytes from i.m. vaccinated mice were stimulated with SARS-CoV-2 spike and analyzed for cytokine secretion by ELISA. Statistical analysis was performed using an unpaired two-tailed Student's $t$ test $\left({ }^{*}, p<0.05\right.$; ${ }^{* *}, p<$ $0.01 ; * * *, p<0.001 ; * * * *, p<0.0001)$.

negative charge and stability issues, mRNA molecules need suitable agents for intracellular delivery. LNPs are one of the most clinically advanced and commonly used tool for mRNA delivery. $^{24}$

In the present study, we developed LNPs-encapsulated mRNA as a vaccine platform. Ionizable amino lipid is a key component in LNP activity. The structure of the ionizable lipid affects the efficiency of endosomal escape of RNA by disrupting endosomal membrane. ${ }^{6}$ Our previous work demonstrated several ionizable lipids for efficient delivery of RNAi to leukocytes. However, mRNA is completely different by size, structure, and function compared to RNAi. Toward this, several structurally different lipids were chosen from our previous work, among them lipid \#10 is the most efficient for RNAi delivery. ${ }^{14}$ Lipids \#2 and \#5 contain hydrazine linker, while lipids \#10, \#14, and \#15 contain ethanolamine linker. However, the hydrophobic lipid tails are chosen from fusogenic linoleic tails or acid-sensitive hydrophobic tails. A previous report also suggested that acid-sensitive lipid tails can improve biocompatibility and may enhance the RNAi delivery efficiency. ${ }^{25}$

We compared these lipids in the form of LNPs for their ability to deliver mRNA and facilitate protein expression in mice, by employing commonly used routes of administration. First, we conducted a luciferase-based screen to evaluate protein expression efficiency and kinetics. IVIS data showed that two of these formulations, LNPs \#14 and \#15, demonstrated higher potency in terms of both level and duration of luciferase expression compared to other lipids, specifically lipid \#10 which was highly efficient for RNAi delivery (Figure 2). Superior luciferase expression for lipids \#14 and \#15 could be attributed to the presence of acidsensitive hydrophobic tails compared to lipid \#10 that contains more stable linoleic tails. Our previous study also demonstrated that ethanolamine linker was more efficient than hydrazine linker. However, the linoleic lipid tails are better than acid-sensitive lipid tails for siRNA transfection. It is difficult to predict the mRNA-LNP efficiency based on RNAi delivery efficiency due to differences in structure, size, and mode of action of different nucleic acid types.

Next, we examined the immunologic response that developed against the expressed luciferase protein. The immunogenicity of the luciferase protein has been demonstrated previously, ${ }^{26}$ and we sought to investigate whether in vivo mRNA delivery efficiency would correlate with the resulting immunogenic responses. While the humoral response was rather limited, as one would expect after a single immunization, a substantial cellular response was recorded against the luciferase protein. Interestingly, immunization with LNP \#2 led to a robust cellular immune response that was comparable to that of LNP \#14 despite a lower and shorterlived luminescent signal (Figure 3). The lack of correlation between expression and immunogenicity has been demonstrated before in a more comprehensive study. ${ }^{25}$ The elicitation of a significant immune response depends ultimately on the extent to which the delivered antigen is taken up by antigen presenting cells (APC), which migrate to lymph nodes and induce $\mathrm{T}$ cell activation and subsequent production of immune mediators. It is therefore possible that, in the case of LNP \#2, while the IVIS data indicated a relatively more limited pattern of luciferase expression, the tissues and cell types in which the protein was expressed enabled the establishment of a more robust immune response. This issue will be further addressed in future studies that will evaluate tissue and organspecific luciferase expression.

Given the robust cellular response observed in animals injected with LNPs \#2 and \#14, these formulations were used for the subsequent vaccination experiment with SARS-CoV-2 $\mathrm{RBD}-\mathrm{hFc}$ mRNA. The RBD protein was chosen as an antigen for immunization on the basis of recent data demonstrating the importance of the RBD domain in SARS-CoV-2 vaccine design, by elicitation of protective immunity by an RBD-based DNA vaccine ${ }^{27}$ and a recombinant $R B D$-based vaccine. ${ }^{28-30}$

In order to enhance the immunologic response to the RBD protein, we used RBD-hFc-fusion protein as the antigen for vaccination (either as mRNA or recombinant protein). Fc fusion has been shown to possess adjuvant activity, promoting both cellular and humoral immune responses, possibly due to enhanced stability, solubility, and delivery, in addition to interaction with $\mathrm{Fc} \gamma$ receptors on antigen presenting cells. ${ }^{20}$ Mice were vaccinated in a prime-boost regimen with naked RBD-hFc mRNA, LNP-encapsulated RBD-hFc mRNA, or recombinant RBD-hFc (Figure 4).

First, naked RBD-hFc mRNA immunization was unable to elicit detectable humoral or cellular responses before or after the boost, suggesting that the mRNA was most likely degraded and was incapable of triggering an effective immune response. Conversely, mice immunized with LNP RBD-hFc mRNA developed substantial antispike IgG titers, a robust cellular response, and high levels of neutralizing antibodies after boost administration in both intramuscular and intradermal groups. Interestingly, while the preboost humoral response was largely 
undetected in these immunization groups, ELISpot analysis demonstrated that a cellular response could be detected at that early stage, particularly in mice immunized intramuscularly, demonstrating the importance of characterization of the cellular response in SARS-CoV-2 immunization studies (Figure 4). While the two LNP formulations, \#2 and \#14, led to comparable humoral and cellular responses in intramuscularly immunized mice, formulation \#14 exhibited superior immunogenicity following intradermal administration of LNP RBDhFc mRNA. This effect was most pronounced at the PRNT assay results (Figure 4C, middle panel). The observed cellular responses induced by LNP \#14 may be attributed to their ability to activate APC via i.d. and i.m. administration, whereas LNP \#2 is proficient via i.m. route only. This interesting observation suggests that not only LNPs' structure but also the route of administration needs to be considered for future clinical development of vaccines. A large number of recombinant protein vaccines are currently in preclinical development, and several spike/RBD-based vaccines have entered clinical trials. ${ }^{2}$ In order to evaluate the relative efficiency of our LNP-based mRNA vaccine, we performed a recombinant protein immunization experiment in parallel, using a standard protein immunization protocol (a primeboost s.c. administration of recombinant protein in the presence of an adjuvant). ${ }^{31}$ Although displaying comparable anti-RBD IgG and spike-pseudotyped VSV neutralizing titers, the recombinant RBD-hFc immunization was unable to mount a significant cellular response as was recorded in the LNP RBD-hFc mRNA vaccine groups (Figure 4). These data demonstrate the inherent advantage of mRNA vaccination over recombinant protein vaccination in elicitation of cellular immune response and are in agreement with a recent study which evaluated the efficacy of a rRBD-Fc vaccine in mice and non-human primates. ${ }^{32}$

While recombinant protein vaccination is dependent upon antigen uptake by APC, intracellular antigen expression following mRNA vaccination eventually leads to efficient peptide epitope MHC class I presentation which facilitates cytolytic $\mathrm{T}$ lymphocyte priming (in addition to helper $\mathrm{T}$ cell response). This combined activation of the two $\mathrm{T}$ cell subtypes yields a robust, long-term humoral and cellular response, which may account for the apparent cellular response we observe following LNP RBD-hFc mRNA vaccination, and not after recombinant $\mathrm{RBD}-\mathrm{hFc}$ immunization.

Two major concerns in the development of a safe SARS$\mathrm{CoV}-2$ vaccine is antibody-dependent enhancement (ADE) and vaccine-associated enhanced respiratory disease (VAERD), which could worsen the clinical manifestations of infection. ${ }^{33}$ Since these two phenomena have been linked with a $\mathrm{T}$ helper 2-cell-biased response, ${ }^{33}$ we evaluated Th1 (IFN $\gamma$, IL-2) and Th2 (IL-4, IL-10) cytokine secretion in response to stimulation of splenocytes from vaccinated mice with SARSCoV-2 spike. Our data demonstrate that both mRNA LNP formulations induced a Th1-biased cellular response toward the spike protein.

\section{CONCLUSIONS}

To conclude the current study, we report here an LNP-based $\mathrm{RBD}-\mathrm{hFc}$ mRNA vaccine which was designed using a preliminary in vivo screen of structurally different ionizable lipid-based LNPs. Several groups have recently reported evidence of immunogenicity and efficacy of LNP-based RBD mRNA vaccines; ${ }^{34-39}$ however, these studies did not pursue the effect of LNP lipid composition on immunogenicity. The physicochemical properties of the ionizable lipids may have dramatic effects on delivery and protein expression efficiency and should be considered upon LNP-based mRNA vaccine design.

Thus, the study documented in this report substantiates the concept that the development of an efficacious LNP-based mRNA vaccine in general and LNP-based RBD-hFc mRNA vaccine in particular may benefit from a judicious inspection of the lipid component of the formulation.

\section{METHODS}

Animals. Female BALB/c mice (6-8 weeks old) were obtained from Charles River and randomly assigned into cages in groups of 10 animals. The mice were allowed free access to water and rodent diet (Harlan, Israel). All animal experiments were conducted in accordance with the guideline of the Israel Institute for Biological Research (IIBR) animal experiments committee: protocol numbers M-60-19 and M-30-20.

Production of SARS-CoV-2 Antigens for Immunization and In Vitro Assays. Recombinant SARS-CoV-2 spike glycoprotein for ELISA and human Fc-RBD-fused protein for vaccination were expressed in pcDNA3. $1^{+}$plasmid, as recently described. ${ }^{38}$ A stabilized soluble version of the spike protein (based on GenPept:QHD43416 ORF amino acids 1-1207) was designed to include proline substitutions at positions 986 and 987, and disruptive replacement of the furin cleavage site RRAR (residues at positions 682-685) with GSAS. C-terminal his-tag, as well as a strep-tag, was included in order to facilitate protein purification. Expression of the recombinant proteins was performed using an ExpiCHO Expression system (Thermoscientific, USA, Cat. No. A29133) following purification using HisTrap (GE Healthcare, U.K.) and Strep-TactinXT (IBA, Germany). The purified protein was sterile-filtered and stored in PBS.

Human Fc-RBD-fused protein (amino acid sequence provided in Supporting Information Figure S2) was expressed using previously designed $\mathrm{Fc}$-fused protein expression vector, ${ }^{17}$ giving rise to a protein comprising two RBD moieties (amino acids 331-524; see accession number of the $S$ protein above) owing to the homodimeric human $(\gamma 1) \mathrm{Fc}$ domain $(\mathrm{huFc})$. Expression of the recombinant proteins was performed using the ExpiCHO Expression system (Thermoscientific) following purification using HiTrap Protein-A column (GE Healthcare). The purified protein was sterile-filtered and stored in PBS.

mRNA. CleanCap firefly luciferase mRNA was a kind gift from BioNtech RNA Pharmaceuticals (Mainz, Germany). CleanCap, pseudouridine-substituted Fc-conjugated RBD mRNA (331-524 aa) was purchased from TriLink Bio Technologies (San Diego, CA, USA). The Fc-conjugated RBD mRNA was designed to include the exact translated $\mathrm{RBD}-\mathrm{hFc}$ protein sequence as the recombinant protein.

LNP Preparation and Characterization. LNPs were synthesized by mixing one volume of lipid mixture of ionizable lipid, DSPC, cholesterol, and DMG-PEG (40:10.5:47.5:2 mol ratio) in ethanol and three volumes of mRNA ( $1: 23(\mathrm{w} / \mathrm{w})$ mRNA to lipid) in acetate buffer. Lipids and mRNA were injected in to a microfluidic mixing device Nanoassemblr (Precision Nanosystems, Vancouver, BC, Canada) at a combined flow rate of $12 \mathrm{~mL} / \mathrm{min}$. The resultant mixture was dialyzed against phosphate buffered saline (PBS; $\mathrm{pH} 7.4$ ) for $16 \mathrm{~h}$ to remove ethanol.

Particles in PBS were analyzed for size and uniformity by dynamic light scattering (DLS, Malvern Instruments Ltd., Worcestershire, U.K.). Intensity-size data can be found in Figure S3. RNA encapsulation in LNPs was calculated according to Quant-iT RiboGreen RNA Assay Kit (Thermo Fisher, Waltham, MA, USA).

Animal Vaccination Experiments. For the in vivo LNP formulations screen, groups of 6-8 week old female BALB/c mice were administered intramuscularly (50 $\mu \mathrm{L}$ in both hind legs), intradermally $(100 \mu \mathrm{L})$, or subcutaneously $(100 \mu \mathrm{L})$ with luciferase mRNA $(5 \mu \mathrm{g})$ encapsulated with five different LNP formulations 
(LNPs \#2, \#5, \#10, \#14, and \#15). Luciferase expression was monitored as described in the bioluminescence imaging studies section. At 28 days post-intramuscular injection, serum and spleen were collected from mice for evaluation of the immunologic response that developed toward luciferase.

For RBD-hFc mRNA vaccination studies, groups of 6-8 week old female $\mathrm{BALB} / \mathrm{c}$ mice were administered intramuscularly $(50 \mu \mathrm{L}$ in both hind legs) or intradermally $(100 \mu \mathrm{L})$ with SARS-CoV-2 RBDhFc mRNA $(5 \mu \mathrm{g})$ encapsulated with LNP formulation \#2 or \#14.

For recombinant $\mathrm{RBD}-\mathrm{hFc}$ vaccination studies, groups of $6-8$ week old female $\mathrm{BALB} / \mathrm{c}$ mice were administered subcutaneously $(100 \mu \mathrm{L})$ with $\mathrm{rRBD}-\mathrm{hFc}(10 \mu \mathrm{g}), \mathrm{rRBD}-\mathrm{hFc}$ emulsified in complete/ incomplete Freund's adjuvant (CFA/IFA), or adjuvant alone as control.

Both RBD-hFc mRNA- and rRBD-hFc-immunized animals were boosted at day 25 with the same priming dose administered on day 0 . Serum and spleens were collected on day 23 ("preboost") and 49 ("postboost") for evaluation of immunologic response toward SARSCoV-2 spike and measurement of cytokine secretion.

Bioluminescence Imaging Studies. Bioluminescence imaging was performed with an IVIS Spectrum imaging system (Caliper Life Sciences). Female BALB/c mice were administered D-luciferin (Regis Technologies) at a dose of $150 \mathrm{mg} / \mathrm{kg}$ intraperitoneally. Mice were anesthetized after receiving D-luciferin with a mixture of ketamine $(60$ $\mathrm{mg} / \mathrm{kg})$ and xylazine $(10 \mathrm{mg} / \mathrm{kg})$ and placed on the imaging platform. Mice were imaged at $5 \mathrm{~min}$ postadministration of D-luciferin using an exposure time of $60 \mathrm{~s}$. Bioluminescence values were quantified by measuring photon flux (photons/second) in the region of interest using the Living IMAGE Software provided by Caliper.

ELISA. ELISA was performed for the detection of luciferase- or SARS-CoV-2 spike-specific antibodies in immunized mouse sera. MaxiSORP ELISA plates (Nunc) were precoated with recombinant luciferase $(0.4 \mu \mathrm{g} / \mathrm{mL}$, Promega, \#E1701) or spike protein $(2 \mu \mathrm{g} / \mathrm{mL})$ overnight at $4{ }^{\circ} \mathrm{C}$ in carbonate buffer. Plated were washed three times with PBST (PBS+0.05\% Tween-20) and blocked with 2\% BSA (Sigma-Aldrich, \#A8022) in PBST for $1 \mathrm{~h}$ at $37{ }^{\circ} \mathrm{C}$. After three washes with PBST, plates were incubated with serially diluted mouse sera in PBST/BSA for $1 \mathrm{~h}$ at $37{ }^{\circ} \mathrm{C}$. Following washing, goat antimouse alkaline phosphatase-conjugated IgG (Jackson Immuno Research Laboratories, No. 115-055-003) was added for $1 \mathrm{~h}$ at $37{ }^{\circ} \mathrm{C}$. The plates were washed with PBST and reactions were developed with $p$-nitrophenyl phosphate substrate (PNPP; Sigma-Aldrich, N2765). Plates were read at $405 \mathrm{~nm}$ absorbance, and antibody titers were calculated as the highest serum dilution with an OD value above 2 times the average OD of the negative controls.

Cytokine Assays. Splenocytes from immunized mice were incubated in the presence of SARS-CoV-2 spike protein $(10 \mu \mathrm{g} /$ $\mathrm{mL}$ ). Culture supernatants were harvested $48 \mathrm{~h}$ later and analyzed for cytokines by ELISA techniques with commercially available kits. IL-2 (DY402), IL-4 (DY404), and IL-10 (DY417) kits were obtained from R\&D Systems, Minneapolis, MN, USA.

Murine IFN $\gamma$ ELISpot Assay. Mice spleens were dissociated in GentleMACS C-tubes (Miltenyi Biotec), filtered, treated with Red Blood Cell Lysing Buffer (Sigma-Aldrich, No. R7757), and washed. Pellets were resuspended in $1 \mathrm{~mL}$ of CTL-Test Medium (CTL, No. CTLT 005) supplemented with $1 \%$ fresh glutamine and $1 \mathrm{mM}$ Pen/ Strep (Biological Industries, Israel), and single cell suspensions were seeded into 96-well, high-protein-binding, PVDF filter plates at 400,000 cells/well. Mice were tested individually in duplicates by stimulation with recombinant luciferase $(13 \mu \mathrm{g} / \mathrm{mL}$, Promega, No. E1701), SARS-CoV-2 spike protein $(10 \mu \mathrm{g} / \mathrm{mL})$, Concanavalin A (Sigma-Aldrich, No. 0412; $2 \mu \mathrm{g} / \mathrm{mL}$ ) as positive control, or CTL medium as negative control (no antigen). Cells were incubated with antigens for $24 \mathrm{~h}$, and the frequency of IFN $\gamma$-secreting cells was determined using Murine IFN $\gamma$ Single-Color Enzymatic ELISPOT kit (CTL, No. MIFNG $1 \mathrm{M} / 5$ ) with strict adherence to the manufacturer's instructions. Spot forming units (SFUs) were counted using an automated ELISpot counter (Cellular Technology Ltd.).

Plaque Reduction Neutralization Test. Spike-pseudotyped $\mathrm{VSV}^{39}$ stocks were prepared by infection of Vero E6 cells for several days. When viral cytopathic effect (CPE) was observed, media were collected, clarified by centrifugation, aliquoted, and stored at $-80^{\circ} \mathrm{C}$. Titer of stock was determined by plaque assay using Vero E6 cells.

For plaque reduction neutralization test (PRNT), Vero E6 cells $\left(0.5 \times 10^{6}\right.$ cells/well in 12-well plates) were cultured in DMEM supplemented with $10 \%$ FCS, MEM non-essential amino acids, $2 \mathrm{nM}$ L-glutamine, 100 units $/ \mathrm{mL}$ penicillin, $0.1 \mathrm{mg} / \mathrm{mL}$ streptomycin, and 12.5 units $/ \mathrm{mL}$ Nystatin (Biological Industries, Israel) overnight at 37 ${ }^{\circ} \mathrm{C}, 5 \% \mathrm{CO}_{2}$.

Serum samples were 3-fold serially diluted (ranging from 1:50 to $1: 12,500)$ in $400 \mu \mathrm{L}$ of MEM supplemented with $2 \%$ FCS, MEM non-essential amino acids, $2 \mathrm{nM}$ L-glutamine, 100 units $/ \mathrm{mL}$ penicillin, $0.1 \mathrm{mg} / \mathrm{mL}$ streptomycin, and 12.5 units $/ \mathrm{mL}$ Nystatin. A $400 \mu \mathrm{L}$ aliquot containing $300 \mathrm{PFU} / \mathrm{mL}$ of spike-pseudotyped VSV was then added to each diluted serum sample, and the mixture was incubated at $37{ }^{\circ} \mathrm{C}, 5 \% \mathrm{CO}_{2}$ for $1 \mathrm{~h}$. Monolayers were then washed once with DMEM w/o FBS, and $200 \mu \mathrm{L}$ of each serum-virus mixture was added in triplicate to the cells for $1 \mathrm{~h}$. Virus mixture without serum was used as control. A $1 \mathrm{~mL}$ overlay [MEM containing 2\% FBS and $0.4 \%$ tragacanth (Sigma, Israel)] was added to each well, and plates were incubated at $37{ }^{\circ} \mathrm{C}, 5 \% \mathrm{CO}_{2}$ for $72 \mathrm{~h}$. The number of plaques in each well was determined following media aspiration, cells fixation, and staining with $1 \mathrm{~mL}$ of crystal violet (Biological Industries, Israel). $\mathrm{NT}_{50}$ values were defined as serum dilution at which the plaque number was reduced by $50 \%$, compared to the plaque number of the control (in the absence of serum).

Transmission Electron Microscopy Analysis. A drop of aqueous solution containing LNPs was placed on the carbon-coated copper grid and dried. The morphology of LNPs was analyzed by a JEOL 1200 EX (Japan) transmission electron microscope.

Statistical Analysis. All values are presented as mean plus standard error of the mean (s.e.m.). Antibody titers, neutralizing titers, ELISpot data, and cytokine levels were compared using one- or two-way ANOVAs or $t$ tests as depicted in the figure captions. All statistical analyses were performed using GraphPad Prism 8 statistical software.

\section{ASSOCIATED CONTENT}

\section{(S) Supporting Information}

The Supporting Information is available free of charge at https://pubs.acs.org/doi/10.1021/acsnano.0c10180.

(Figure S1) Description of lipid synthesis procedures; (Figure S2) human Fc-conjugated receptor-binding domain protein sequence; (Figure S3) intensity-size data as recorded by DLS analysis (PDF)

\section{AUTHOR INFORMATION}

\section{Corresponding Authors}

Ofer Cohen - Department of Biochemistry and Molecular Genetics, Israel Institute for Biological Research, Ness-Ziona 76100, Israel; Email: oferc@iibr.gov.il

Dan Peer - Laboratory of Precision NanoMedicine, Shmunis School for Biomedicine and Cancer Research, George S. Wise Faculty of Life Sciences, Tel Aviv University, Tel Aviv 69978, Israel; Center for Nanoscience and Nanotechnology, Department of Materials Sciences and Engineering, Iby and Aladar Fleischman Faculty of Engineering, and Cancer Biology Research Center, Tel Aviv University, Tel Aviv 69978, Israel; 잉oㅇ.org/0000-0001-8238-0673; Email: peer@tauex.tau.ac.il

\section{Authors}

Uri Elia - Laboratory of Precision NanoMedicine, Shmunis School for Biomedicine and Cancer Research, George S. Wise Faculty of Life Sciences, Tel Aviv University, Tel Aviv 69978, Israel; Center for Nanoscience and Nanotechnology, 
Department of Materials Sciences and Engineering, Iby and Aladar Fleischman Faculty of Engineering, and Cancer Biology Research Center, Tel Aviv University, Tel Aviv 69978, Israel; Department of Biochemistry and Molecular Genetics, Israel Institute for Biological Research, Ness-Ziona 76100, Israel

Srinivas Ramishetti - Laboratory of Precision NanoMedicine, Shmunis School for Biomedicine and Cancer Research, George S. Wise Faculty of Life Sciences, Tel Aviv University, Tel Aviv 69978, Israel; Center for Nanoscience and Nanotechnology, Department of Materials Sciences and Engineering, Iby and Aladar Fleischman Faculty of Engineering, and Cancer Biology Research Center, Tel Aviv University, Tel Aviv 69978, Israel

Ronit Rosenfeld - Department of Biochemistry and Molecular Genetics, Israel Institute for Biological Research, Ness-Ziona 76100, Israel

Niels Dammes - Laboratory of Precision NanoMedicine, Shmunis School for Biomedicine and Cancer Research, George S. Wise Faculty of Life Sciences, Tel Aviv University, Tel Aviv 69978, Israel; Center for Nanoscience and Nanotechnology, Department of Materials Sciences and Engineering, Iby and Aladar Fleischman Faculty of Engineering, and Cancer Biology Research Center, Tel Aviv University, Tel Aviv 69978, Israel

Erez Bar-Haim - Department of Biochemistry and Molecular Genetics, Israel Institute for Biological Research, Ness-Ziona 76100, Israel

Gonna Somu Naidu - Laboratory of Precision NanoMedicine, Shmunis School for Biomedicine and Cancer Research, George S. Wise Faculty of Life Sciences, Tel Aviv University, Tel Aviv 69978, Israel; Center for Nanoscience and Nanotechnology, Department of Materials Sciences and Engineering, Iby and Aladar Fleischman Faculty of Engineering, and Cancer Biology Research Center, Tel Aviv University, Tel Aviv 69978, Israel

Efi Makdasi - Department of Infectious Diseases, Israel Institute for Biological Research, Ness-Ziona 76100, Israel

Yfat Yahalom-Ronen - Department of Infectious Diseases, Israel Institute for Biological Research, Ness-Ziona 76100, Israel

Hadas Tamir - Department of Infectious Diseases, Israel Institute for Biological Research, Ness-Ziona 76100, Israel

Nir Paran - Department of Infectious Diseases, Israel Institute for Biological Research, Ness-Ziona 76100, Israel

Complete contact information is available at: https://pubs.acs.org/10.1021/acsnano.0c10180

\section{Notes}

The authors declare the following competing financial interest(s): D.P. receives licensing fees (to patents on which he was an inventor) from, invested in, consults (or on scientific advisory boards or boards of directors) for, lectured (and received a fee) or conducts sponsored research at TAU for the following entities: Alnylam Pharmaceuticals Inc., Arix Biosciences Inc., ART Biosciences, BioNtech RNA Pharmaceuticals, Centricus, Diagnostear Ltd., EPM Inc., Earli Inc., lmpetis Biosciences, Kernal Biologics, GPCR Inc., Medison Pharma Ltd., Newphase Ltd., NLC Pharma Ltd., Nanocell Therapeutics, NanoGhosts Ltd., Precision Nanosystems Inc., Paul Hastings Inc., Regulon, Roche, SciCann, Shire Inc., SirTLabs Corporation, VLX Ventures, TATA Cooperation, Teva
Pharmaceuticals Inc., and Wize Pharma Ltd. All other authors declare no competing financial interests.

All relevant data are available from the authors upon reasonable request.

This work has been previously uploaded to a preprint server: Elia, U.; Ramishetti, S.; Dammes, N.; Bar-Haim, E.; Naidu, G.S.; Makdasi, E.; Cohen, O.; Peer, D. Design of SARS-CoV-2 RBD mRNA VaccineUsing Novel Ionizable Lipids. bioRxiv (Immunology)Oct. 15, 2020, 2020.10.15.341537. https://www. biorxiv.org/content/10.1101/2020.10.15.341537v1.

\section{ACKNOWLEDGMENTS}

This work was supported by the Lewis Trust grant to D.P. We thank Shahar Rotem, Hila Cohen, Ma'ayan Israeli, Adi Bercovich-Kinori, Liat Bar-On, Theodor Chitlaru, Shirley Lazar, Ron Alcalay, Tal Noy-Porat, and Yinon Levi for their assistance and support and Shmuel Yitzhaki, Ohad Mazor, and Emanuelle Mamroud for their fruitful discussions and encouragement. We also thank Amir Rosner, Beni Shareabi, and Yossi Schlomovitch for animal husbandry.

\section{REFERENCES}

(1) Coronavirus Disease (COVID-19), World Health Organization, Oct. 11, 2020; https://www.who.int/docs/default-source/ coronaviruse/situation-reports/20201012-weekly-epi-update-9.pdf (accessed 2020-10-12).

(2) Draft Landscape of COVID-19 Candidate Vaccines, World Health Organization; https://www.who.int/publications/m/item/draftlandscape-of-covid-19-candidate-vaccines (accessed 2020-10-02).

(3) Jackson, L. A.; Anderson, E. J.; Rouphael, N. G.; Roberts, P. C.; Makhene, M.; Coler, R. N.; McCullough, M. P.; Chappell, J. D.; Denison, M. R.; Stevens, L. J.; Pruijssers, A. J.; McDermott, A.; Flach, B.; Doria-Rose, N. A.; Corbett, K. S.; Morabito, K. M.; O’Dell, S.; Schmidt, S. D.; Swanson, P. A., 2nd; Padilla, M.; et al. An mRNA Vaccine against SARS-CoV-2 - Preliminary Report. N. Engl. J. Med. 2020, 383, 1920-1931.

(4) Adams, D.; Gonzalez-Duarte, A.; O’Riordan, W. D.; Yang, C. C.; Ueda, M.; Kristen, A. V.; Tournev, I.; Schmidt, H. H.; Coelho, T.; Berk, J. L.; Lin, K. P.; Vita, G.; Attarian, S.; Plante-Bordeneuve, V.; Mezei, M. M.; Campistol, J. M.; Buades, J.; Brannagan, T. H., 3rd; Kim, B. J.; Oh, J.; et al. Patisiran, an RNAi Therapeutic, for Hereditary Transthyretin Amyloidosis. N. Engl. J. Med. 2018, 379, 11-21.

(5) Ramishetti, S.; Landesman-Milo, D.; Peer, D. Advances in RNAi Therapeutic Delivery to Leukocytes Using Lipid Nanoparticles. J. Drug Targeting 2016, 24, 780-786.

(6) Semple, S. C.; Akinc, A.; Chen, J.; Sandhu, A. P.; Mui, B. L.; Cho, C. K.; Sah, D. W.; Stebbing, D.; Crosley, E. J.; Yaworski, E.; Hafez, I. M.; Dorkin, J. R.; Qin, J.; Lam, K.; Rajeev, K. G.; Wong, K. F.; Jeffs, L. B.; Nechev, L.; Eisenhardt, M. L.; Jayaraman, M.; et al. Rational Design of Cationic Lipids for siRNA Delivery. Nat. Biotechnol. 2010, 28, 172-6.

(7) Yonezawa, S.; Koide, H.; Asai, T. Recent Advances in siRNA Delivery Mediated by Lipid-Based Nanoparticles. Adv. Drug Delivery Rev. 2020, 154, 64-78.

(8) Alberer, M.; Gnad-Vogt, U.; Hong, H. S.; Mehr, K. T.; Backert, L.; Finak, G.; Gottardo, R.; Bica, M. A.; Garofano, A.; Koch, S. D.; Fotin-Mleczek, M.; Hoerr, I.; Clemens, R.; von Sonnenburg, F. Safety and Immunogenicity of a mRNA Rabies Vaccine in Healthy Adults: An Open-Label, Non-Randomised, Prospective, First-in-Human Phase 1 Clinical Trial. Lancet 2017, 390, 1511-1520.

(9) Bahl, K.; Senn, J. J.; Yuzhakov, O.; Bulychev, A.; Brito, L. A.; Hassett, K. J.; Laska, M. E.; Smith, M.; Almarsson, O.; Thompson, J.; Ribeiro, A. M.; Watson, M.; Zaks, T.; Ciaramella, G. Preclinical and Clinical Demonstration of Immunogenicity by mRNA Vaccines against H10N8 and H7N9 Influenza Viruses. Mol. Ther. 2017, 25, 1316-1327. 
(10) John, S.; Yuzhakov, O.; Woods, A.; Deterling, J.; Hassett, K.; Shaw, C. A.; Ciaramella, G. Multi-Antigenic Human Cytomegalovirus mRNA Vaccines that Elicit Potent Humoral and Cell-Mediated Immunity. Vaccine 2018, 36, 1689-1699.

(11) Pardi, N.; Hogan, M. J.; Pelc, R. S.; Muramatsu, H.; Andersen, H.; DeMaso, C. R.; Dowd, K. A.; Sutherland, L. L.; Scearce, R. M.; Parks, R.; Wagner, W.; Granados, A.; Greenhouse, J.; Walker, M.; Willis, E.; Yu, J. S.; McGee, C. E.; Sempowski, G. D.; Mui, B. L.; Tam, Y. K.; et al. Zika Virus Protection by a Single Low-Dose NucleosideModified mRNA Vaccination. Nature 2017, 543, 248-251.

(12) Pardi, N.; Secreto, A. J.; Shan, X.; Debonera, F.; Glover, J.; Yi, Y.; Muramatsu, H.; Ni, H.; Mui, B. L.; Tam, Y. K.; Shaheen, F.; Collman, R. G.; Kariko, K.; Danet-Desnoyers, G. A.; Madden, T. D.; Hope, M. J.; Weissman, D. Administration of Nucleoside-Modified mRNA Encoding Broadly Neutralizing Antibody Protects Humanized Mice from HIV-1 Challenge. Nat. Commun. 2017, 8, 14630.

(13) Sahin, U.; Muik, A.; Derhovanessian, E.; Vogler, I.; Kranz, L. M.; Vormehr, M.; Baum, A.; Pascal, K.; Quandt, J.; Maurus, D.; Brachtendorf, S.; Lorks, V.; Sikorski, J.; Hilker, R.; Becker, D.; Eller, A. K.; Grutzner, J.; Boesler, C.; Rosenbaum, C.; Kuhnle, M. C.; et al. COVID-19 Vaccine BNT162b1 Elicits Human Antibody and TH1 TCell Responses. Nature 2020, 586, 594-599.

(14) Ramishetti, S.; Hazan-Halevy, I.; Palakuri, R.; Chatterjee, S.; Naidu Gonna, S.; Dammes, N.; Freilich, I.; Kolik Shmuel, L.; Danino, D.; Peer, D. A Combinatorial Library of Lipid Nanoparticles for RNA Delivery to Leukocytes. Adv. Mater. 2020, 32, No. 1906128.

(15) Shang, J.; Ye, G.; Shi, K.; Wan, Y.; Luo, C.; Aihara, H.; Geng, Q.; Auerbach, A.; Li, F. Structural Basis of Receptor Recognition by SARS-CoV-2. Nature 2020, 581, 221-224.

(16) Czajkowsky, D. M.; Hu, J.; Shao, Z.; Pleass, R. J. Fc-Fusion Proteins: New Developments and Future Perspectives. EMBO Mol. Med. 2012, 4, 1015-28.

(17) Noy-Porat, T.; Cohen, O.; Ehrlich, S.; Epstein, E.; Alcalay, R.; Mazor, O. Acetylcholinesterase-Fc Fusion Protein (AChE-Fc): A Novel Potential Organophosphate Bioscavenger with Extended Plasma Half-Life. Bioconjugate Chem. 2015, 26, 1753-8.

(18) Schmidt, S. R. Fusion-Proteins as BiopharmaceuticalsApplications and Challenges. Curr. Opin. Drug Discovery Dev. 2009, 12, 284-295.

(19) Soleimanpour, S.; Hassannia, T.; Motiee, M.; Amini, A. A.; Rezaee, S. A. Fcgamma1 Fragment of IgG1 as a Powerful Affinity Tag in Recombinant Fc-Fusion Proteins: Immunological, Biochemical and Therapeutic Properties. Crit. Rev. Biotechnol. 2017, 37, 371-392.

(20) Wieland, A.; Ahmed, R. Fc Receptors in Antimicrobial Protection. Curr. Top. Microbiol. Immunol. 2019, 423, 119-150.

(21) Duivelshof, B. L.; Murisier, A.; Camperi, J.; Fekete, S.; Beck, A.; Guillarme, D.; D'Atri, V. Therapeutic Fc-Fusion Proteins: Current Analytical Strategies. J. Sep. Sci. 2021, 44, 35-62.

(22) Grifoni, A.; Weiskopf, D.; Ramirez, S. I.; Mateus, J.; Dan, J. M.; Moderbacher, C. R.; Rawlings, S. A.; Sutherland, A.; Premkumar, L.; Jadi, R. S.; Marrama, D.; de Silva, A. M.; Frazier, A.; Carlin, A. F.; Greenbaum, J. A.; Peters, B.; Krammer, F.; Smith, D. M.; Crotty, S.; Sette, A. Targets of T Cell Responses to SARS-CoV-2 Coronavirus in Humans with COVID-19 Disease and Unexposed Individuals. Cell 2020, 181, 1489-1501.e15.

(23) Zheng, H. Y.; Zhang, M.; Yang, C. X.; Zhang, N.; Wang, X. C.; Yang, X. P.; Dong, X. Q.; Zheng, Y. T. Elevated Exhaustion Levels and Reduced Functional Diversity of T Cells in Peripheral Blood May Predict Severe Progression in COVID-19 Patients. Cell. Mol. Immunol. 2020, 17, 541-543.

(24) Ickenstein, L. M.; Garidel, P. Lipid-Based Nanoparticle Formulations for Small Molecules and RNA Drugs. Expert Opin. Drug Delivery 2019, 16, 1205-1226.

(25) Hassett, K. J.; Benenato, K. E.; Jacquinet, E.; Lee, A.; Woods, A.; Yuzhakov, O.; Himansu, S.; Deterling, J.; Geilich, B. M.; Ketova, T.; Mihai, C.; Lynn, A.; McFadyen, I.; Moore, M. J.; Senn, J. J.; Stanton, M. G.; Almarsson, O.; Ciaramella, G.; Brito, L. A. Optimization of Lipid Nanoparticles for Intramuscular Administration of mRNA Vaccines. Molecular therapy. Mol. Ther.-Nucleic Acids 2019, 15, 1-11.

(26) Petkov, S. P.; Heuts, F.; Krotova, O. A.; Kilpelainen, A.; Engstrom, G.; Starodubova, E. S.; Isaguliants, M. G. Evaluation of Immunogen Delivery by DNA Immunization Using Non-Invasive Bioluminescence Imaging. Hum. Vaccines Immunother. 2013, 9, 222836.

(27) Lainšček, D.; Fink, T.; Forstnerǐ̌, V.; Hafner-Bratkovič, I.; Orehek, S.; Strmšek, Ž.; Manček-Keber, M.; Pečan, P.; Esih, H.; Malenšek, S.; Aupič, J.; Dekleva, P.; Plaper, T.; Vidmar, S.; Kadunc, L.; Benčina, M.; Omersa, N.; Anderluh, G.; Pojer, F.; Lau, K.; et al. Immune Response to Vaccine Candidates Based on Different Types of Nanoscaffolded RBD Domain of the SARS-CoV-2 Spike Protein. bioRxiv (Immunology), Aug. 28, 2020, 2020.08.28.244269. https:// www.biorxiv.org/content/10.1101/2020.08.28.244269v1 (accessed 2020-10-12).

(28) Yang, J.; Wang, W.; Chen, Z.; Lu, S.; Yang, F.; Bi, Z.; Bao, L.; Mo, F.; Li, X.; Huang, Y.; Hong, W.; Yang, Y.; Zhao, Y.; Ye, F.; Lin, S.; Deng, W.; Chen, H.; Lei, H.; Zhang, Z.; Luo, M.; et al. A Vaccine Targeting the RBD of the $S$ Protein of SARS-CoV-2 Induces Protective Immunity. Nature 2020, 586, 572-577.

(29) Liu, Z.; Xu, W.; Xia, S.; Gu, C.; Wang, X.; Wang, Q.; Zhou, J.; Wu, Y.; Cai, X.; Qu, D.; Ying, T.; Xie, Y.; Lu, L.; Yuan, Z.; Jiang, S. RBD-Fc-Based COVID-19 Vaccine Candidate Induces Highly Potent SARS-CoV-2 Neutralizing Antibody Response. Signal Transduction Targeted Ther. 2020, 5, 282.

(30) Liu, X.; Drelich, A.; Li, W.; Chen, C.; Sun, Z.; Shi, M.; Adams, C.; Mellors, J. W.; Tseng, C. T.; Dimitrov, D. S. Enhanced Elicitation of Potent Neutralizing Antibodies by the SARS-CoV-2 Spike Receptor Binding Domain Fc Fusion Protein in Mice. Vaccine 2020, 38, 7205-7212.

(31) Du, L.; Zhao, G.; He, Y.; Guo, Y.; Zheng, B. J.; Jiang, S.; Zhou, Y. Receptor-Binding Domain of SARS-CoV Spike Protein Induces Long-Term Protective Immunity in an Animal Model. Vaccine 2007, $25,2832-8$.

(32) Sun, S.; He, L.; Zhao, Z.; Gu, H.; Fang, X.; Wang, T.; Yang, X.; Chen, S.; Deng, Y.; Li, J.; Zhao, J.; Li, L.; Li, X.; He, P.; Li, G.; Li, H.; Zhao, Y.; Gao, C.; Lang, X.; Wang, X., et al. Recombinant Fc-Fusion Vaccine of RBD Induced Protection against SARS-CoV-2 in NonHuman Primate and Mice. bioRxiv (Immunology), Nov. 30, 2020, 2020.11.29.402339. https://www.biorxiv.org/content/10.1101/2020. 11.29.402339v1 (accessed 2020-10-12).

(33) Graham, B. S. Rapid COVID-19 Vaccine Development. Science 2020, 368, 945-946.

(34) Laczko, D.; Hogan, M. J.; Toulmin, S. A.; Hicks, P.; Lederer, K.; Gaudette, B. T.; Castano, D.; Amanat, F.; Muramatsu, H.; Oguin, T. H., 3rd; Ojha, A.; Zhang, L.; Mu, Z.; Parks, R.; Manzoni, T. B.; Roper, B.; Strohmeier, S.; Tombacz, I.; Arwood, L.; Nachbagauer, R.; et al. A Single Immunization with Nucleoside-Modified mRNA Vaccines Elicits Strong Cellular and Humoral Immune Responses against SARS-CoV-2 in Mice. Immunity 2020, 53, 724-732.

(35) Lu, J.; Lu, G.; Tan, S.; Xia, J.; Xiong, H.; Yu, X.; Qi, Q.; Yu, X.; Li, L.; Yu, H.; Xia, N.; Zhang, T.; Xu, Y.; Lin, J. A COVID-19 mRNA Vaccine Encoding SARS-CoV-2 Virus-Like Particles Induces a Strong Antiviral-Like Immune Response in Mice. Cell Res. 2020, 30, 936939.

(36) Tai, W.; Zhang, X.; Drelich, A.; Shi, J.; Hsu, J. C.; Luchsinger, L.; Hillyer, C. D.; Tseng, C. K.; Jiang, S.; Du, L. A Novel ReceptorBinding Domain (RBD)-Based mRNA Vaccine against SARS-CoV-2. Cell Res. 2020, 30, 932-935.

(37) Zhang, N. N.; Li, X. F.; Deng, Y. Q.; Zhao, H.; Huang, Y. J.; Yang, G.; Huang, W. J.; Gao, P.; Zhou, C.; Zhang, R. R.; Guo, Y.; Sun, S. H.; Fan, H.; Zu, S. L.; Chen, Q.; He, Q.; Cao, T. S.; Huang, X. Y.; Qiu, H. Y.; Nie, J. H.; et al. A Thermostable mRNA Vaccine against COVID-19. Cell 2020, 182, 1271-1283.e16.

(38) Noy-Porat, T.; Makdasi, E.; Alcalay, R.; Mechaly, A.; Levy, Y.; Bercovich-Kinori, A.; Zauberman, A.; Tamir, H.; Yahalom-Ronen, Y.; Israeli, M.; Epstein, E.; Achdout, H.; Melamed, S.; Chitlaru, T.; Weiss, S.; Peretz, E.; Rosen, O.; Paran, N.; Yitzhaki, S.; Shapira, S. C.; et al. A 
Panel of Human Neutralizing mAbs Targeting SARS-CoV-2 Spike at Multiple Epitopes. Nat. Commun. 2020, 11, 4303.

(39) Yahalom-Ronen, Y.; Tamir, H.; Melamed, S.; Politi, B.; Shifman, O.; Achdout, H.; Vitner, E. B.; Israeli, O.; Milrot, E.; Stein, D.; Cohen-Gihon, I.; Lazar, S.; Gutman, H.; Glinert, I.; Cherry, L.; Vagima, Y.; Lazar, S.; Weiss, S.; Ben-Shmuel, A.; Avraham, R.; Puni, R.; et al. A Single Dose of Recombinant VSV-G-Spike Vaccine Provides Protection against SARS-CoV-2 Challenge. Nat. Commun. 2020, 11, 6402. 